Available online on 15.1.2017 at http://ujpr.org
Universal Journal of Pharmaceutical Research
An International Peer Reviewed Journal
Open access to Pharmaceutical research

\title{
ABACAVIR LOADED NANOPARTICLES: PREPARATION, PHYSICOCHEMICAL CHARACTERIZATION AND IN VITRO EVALUATION

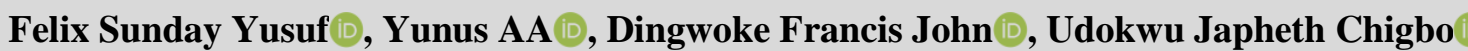 Department of Biochemistry, Ahmadu Bello University, P. M. B. 1045, Samaru, Zaria, Kaduna, Nigeria
}

\section{ABSTRACT}

Objectives: Abacavir is a nucleoside analog reverse transcriptase inhibitor (NRTI), antiretroviral drug; it is used in treatment of AIDS. The present study deals with the formulation and evaluation of Abacavir nanoparticles.

Methods: Abacavir nanoparticles were formulated by solvent displacement method using Eudragit RL-100, chitosan and Poloxamer-188. Nanoparticles were characterized by determining its particle size, drug entrapment efficiency, particle morphological character and in-vitro drug release.

Results: Particle size range of nanoparticles was in the range of 121.4-140.6 nm. Zeta potential of formulations was determined, and it was found in range of 16.5-20.45 mv. The in-vitro release of nanoparticles were carried out which exhibited a sustained release of Abacavir from nanoparticles up to $10 \mathrm{hrs}$.

Conclusion: The study concludes that nanoparticles can be a promising drug delivery system for sustained release of Abacavir in terms of increased bioavailability.

Keywords: Abacavir, entrapment efficiency, nanoparticles, solvent displacement method, Zeta potential.

Article Info: Received 3 November 2016; Revised 2 December; Accepted 27 December, Available online 15 January 2017

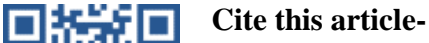

The Yusuf FS, Yunus AA, John DF, Chigbo UJ. Abacavir loaded nanoparticles: preparation, physicochemical 4:- characterization and in vitro evaluation. Universal Journal of Pharmaceutical Research 2016; 1(2): 11-14.

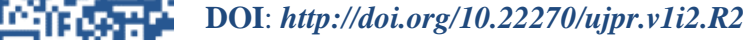

口E A Address for Correspondence

Felix Sunday Yusuf, Department of Biochemistry, Ahmadu Bello University, P. M. B. 1045, Samaru, Zaria, Kaduna, Nigeria, Tel: +2348134339165, E-mail: Phelixsunday@yahoo.com

\section{INTRODUCTION}

Nanoparticles are promising drug delivery systems of controlled and targeted drug release. Nanoparticles are solid colloidal particles with diameters ranging from 1$1000 \mathrm{~nm}$. They possess unique properties like small size, high surface area, and ease of suspending in liquids, deep access to cells and organelles, variable optical and magnetic properties are offered by nanoparticles ${ }^{1}$. Their advantages includes increased bioavailability, site specific drug delivery, sustained release of drug over longer period of time, retention of dosage form and reduction in dosing frequency ${ }^{2}$. Abacavir is a nucleoside analog reverse transcriptase inhibitor (NRTI), antiretroviral drug; it is used in treatment of AIDS. It is used together with other HIV medications, and is not recommended by itself ${ }^{3}$. It has in-vitro activity against a range of HIV-1 and HIV-2 strains. It has been well tolerated, the main side effect is hypersensitivity, this can be severe, and in rare cases, possibility for fatal. It has short half life and frequent administration of it is necessary to maintain its effective plasma concentration ${ }^{4}$. In anti-retroviral therapy, a sustained release drug delivery system is required for reduction of side effects and improving the bioavailability ${ }^{5}$. So, Abacavir is a suitable candidate to develop and evaluate as nanoparticles formulations ${ }^{5}$.

\section{MATERIALS AND METHODS}

Abacavir was a gift sample from Green life Pharmaceuticals Ltd. Eudragit RL-100 was obtained from Neimeth, and chitosan from Emzor Pharmaceuticals. All other chemicals used were of analytical grade.

Preparation of Abacavir nanoparticles

Abacavir nanoparticles were prepared by the solvent displacement method. Drug and various proportions of polymers i.e. Eudragit RL-100, and chitosan were dissolved in acetone. This solution was poured drop wise into solution of poloxamer 188 with magnetic stirring at room temperature. Nanoparticles were spontaneously formed and turned the solution slightly turbid then; acetone was removed by continuous stirring at $35-40^{\circ} \mathrm{C}$. The prepared suspension was centrifuged, supernatant was removed and the sediment was freeze dried for further analysis ${ }^{6}$. 
Particle size, surface morphology and zeta potential The surface morphology (roundness, smoothness, and formation of aggregates) and particle size were studied by scanning electron microscopy. Zeta potential is an abbreviation for electrokinetic potential in colloidal systems ${ }^{7}$. Zeta potential of the formulations was determined by zeta potential probe model DT- 300 .

Table 1: Composition of different Abacavir nanoparticles.

\begin{tabular}{cccccc}
\hline $\begin{array}{c}\text { Formulation } \\
\text { code }\end{array}$ & $\begin{array}{c}\text { Eudragit } \\
\text { RL-100 }(\mathbf{m g})\end{array}$ & $\begin{array}{c}\text { Chitosan } \\
(\mathbf{m g})\end{array}$ & $\begin{array}{c}\text { Water } \\
(\mathbf{m l})\end{array}$ & $\begin{array}{c}\text { Acetone } \\
(\mathbf{m l})\end{array}$ & $\begin{array}{c}\text { Poloxamer-188 } \\
(\mathbf{m g})\end{array}$ \\
\hline NP1 & 100 & - & 40 & 10 & 10 \\
NP2 & 200 & - & 40 & 10 & 20 \\
NP3 & - & 100 & 40 & 10 & 30 \\
NP4 & - & 200 & 40 & 10 & 40 \\
\hline
\end{tabular}

\section{Drug content}

The drug content in each formulation was determined by weighing nanoparticles equivalent to $30 \mathrm{mg}$ of Abacavir and dissolving in $100 \mathrm{ml}$ of $6.8 \mathrm{pH}$ phosphate buffer, followed by stirring. The solution was filtered through a $0.45 \mu$ membrane filter, diluted suitably and the absorbance of resultant solution was measured spectrophotometrically at $271 \mathrm{~nm}$ using $6.8 \mathrm{pH}$ phosphate buffer as blank ${ }^{8}$. The drug content of the prepared nanoparticles was determined by the formula:

$$
\% \text { Drug content }=\frac{\text { Weight of drug in nanoparticles }}{\text { Weight of nanoparticles }} \times 100
$$

\section{Nanoparticles recovery}

The recovery of nanoparticles suspension was analyzed by centrifugation method, where $10 \mathrm{ml}$ suspension was centrifuged at $15000 \mathrm{rpm}$ at $4^{\circ} \mathrm{C}$. The sediment nanoparticles were collected, freeze dried and calculated for $\%$ yield ${ }^{9}$.

$$
\% \text { Yield }=\frac{\text { Weight of recovered particles }}{\text { Weight of drug and polymer used }} \times 100
$$

\section{Drug entrapment efficiency}

$15 \mathrm{mg}$ of freeze dried nanoparticles were taken in a volumetric flask filled with distilled water for extraction of drug and kept for 24 hours. The mixture was sonicated for $20 \mathrm{~min}$. Then filtered by using vacuum filter to obtain complete clear solution and sample will be assayed by UV-spectrophotometer at $271 \mathrm{~nm}^{10}$.

$$
\% \text { DEE }=\frac{\text { Weight of drug in nanoparticles }}{\text { Weight of drug used }} \times 100
$$

\section{In vitro release studies}

In vitro release studies were carried out by using dialysis tubes with an artificial membrane. The prepared Abacavir nanoparticles and $10 \mathrm{ml}$ of phosphate buffer $\mathrm{pH} 7.4$ was added to the dialysis tube and subjected to dialysis by immersing the dialysis tube to the receptor compartment containing $250 \mathrm{ml}$ of phosphate buffer $\mathrm{pH}$ 6.8. The medium in the receptor was agitated continuously using a magnetic stirrer a temperature was maintained at $37 \pm 1^{\circ} \mathrm{C}$. $5 \mathrm{ml}$ of sample of receptor compartment were taken at various intervals of time over a period of $24 \mathrm{~h}$ and each time fresh buffer was replaced. The amount of drug released was determined spectrometrically at $271 \mathrm{~nm}^{11}$.

Kinetic modeling

In order to understand the kinetic and mechanism of drug release, the result of in vitro drug release study of nanoparticles were fitted with various kinetic equation like zero order, first order and Higuchi'smodel ${ }^{12}$.

\section{RESULTS AND DISCUSSION}

Four different Abacavir nanoparticles formulations were prepared by the solvent displacement method with varying proportions of Eudragit RL-100, and chitosan. The scanning electron microphotograph indicate that Abacavir nanoparticles have a discrete spherical structure without aggregation.

Table 2: Physicochemical characterization of Abacavir nanoparticles.

\begin{tabular}{cccccc}
\hline $\begin{array}{c}\text { Formulation } \\
\text { code }\end{array}$ & $\begin{array}{c}\text { Particle size } \\
(\mathbf{n m})\end{array}$ & $\begin{array}{c}\text { \% Drug } \\
\text { content }\end{array}$ & $\begin{array}{c}\text { \% } \\
\text { Yield }\end{array}$ & $\begin{array}{c}\text { Zeta potential } \\
\text { (mv) }\end{array}$ & $\begin{array}{c}\text { \% Entrapment } \\
\text { efficiency }\end{array}$ \\
\hline NP1 & $121.4 \pm 0.37$ & $70.44 \pm 0.26$ & 59.46 & $16.5 \pm 0.52$ & 99.22 \\
NP2 & $125.5 \pm 0.25$ & $78.32 \pm 0.41$ & 64.38 & $18.31 \pm 0.37$ & 99.45 \\
NP3 & $130.4 \pm 0.71$ & $80.35 \pm 0.82$ & 69.57 & $20.45 \pm 0.41$ & 99.92 \\
NP4 & $140.6 \pm 0.43$ & $84.22 \pm 0.31$ & 70.65 & $19.72 \pm 0.73$ & 99.85 \\
\hline
\end{tabular}

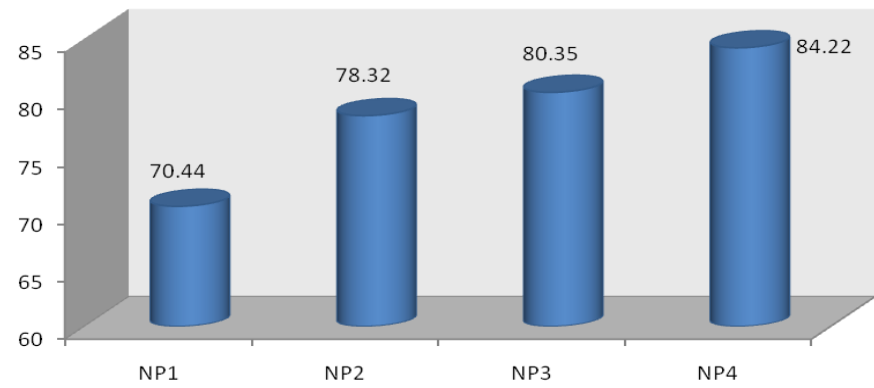

Figure 1: \% Drug content of Abacavir nanoparticles. 
The particle size of nanoparticles varied somewhat among the formulation due to variation in the composition of formulations. Particle size of nanoparticles was in the range of 121.4-140.6 $\mathrm{nm}$. Zeta potential of best formulation was determined and it was found in range of 16.5-20.45 MV. Since there was a decrease of surface potential, it could be concluded that a part of drug was absorbed on the polymeric particles. The drug content was maximum in formulation NP4.

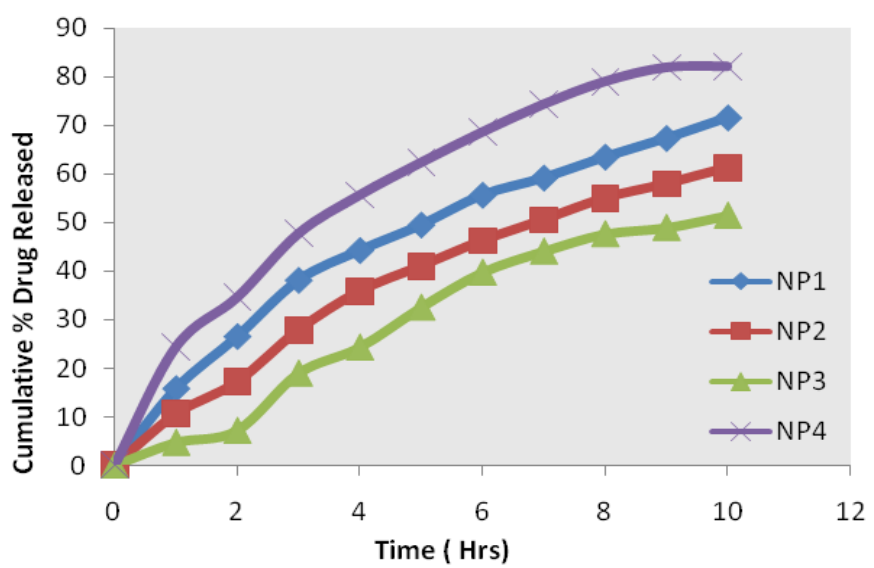

Figure 2: In-vitro drug release profile of Abacavir nanoparticles.

In general nanoparticles exhibited an increase in drug content with an increased in the polymer ratio, up to particular concentration. A decrease in drug content was observed after that point due to the saturation capacity of polymer. The percent entrapment efficiency was found to be more than $99 \%$ in all formulations.

Table 3: Correlation coefficent of different nanoparticles formulations.

\begin{tabular}{cccc}
\hline \multirow{2}{*}{$\begin{array}{c}\text { Formulation } \\
\text { code }\end{array}$} & \multicolumn{3}{c}{ Correlation Coefficient $\left(\mathbf{r}^{\mathbf{2}}\right)$} \\
\cline { 2 - 4 } & $\begin{array}{c}\text { Higuchi } \\
\text { kinetics }\end{array}$ & $\begin{array}{c}\text { First order } \\
\text { kinetics }\end{array}$ & $\begin{array}{c}\text { Zero order } \\
\text { kinetics }\end{array}$ \\
\hline NP1 & 0.993 & 0.882 & 0.956 \\
NP2 & 0.992 & 0.884 & 0.950 \\
NP3 & 0.982 & 0.917 & 0.893 \\
NP4 & 0.976 & 0.925 & 0.900 \\
\hline
\end{tabular}

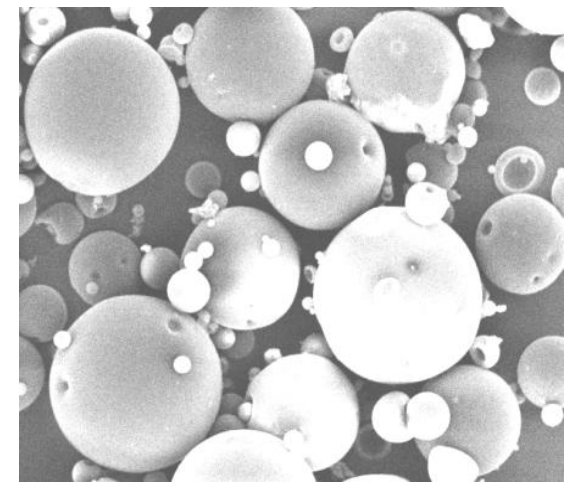

Figure 3: SEM of Abacavir nanaoparticles of batch NP4.

The in-vitro release study was conducted for $10 \mathrm{hrs}$. The release of Abacavir mainly depends upon the polymer concentration. The burst release of Abacavir from nanoparticles at initial stage resulted from the dissolution of drug crystals on the surface of nanoparticles. Nanoparticles of batch NP3 shows maximum release $82.11 \%$ in $10 \mathrm{hrs}$. The in vitro release data was applied to various kinetic models to predict the drug release kinetic mechanism.
Nanoparticles were fitted with various kinetic equations like zero order, first order and Higuchi's model. The release constant was calculated from the slope of appropriate plots, and the regression coefficient $\left(\mathrm{r}^{2}\right)$ was determined by the means of PCP Disso software version 3.0.

\section{CONCLUSION}

The method used for preparation of nanoparticles of Abacavir was found to be simple and reproducible. The slow and constant release of Abacavir from nanoparticles maintain constant drug plasma concentration thereby increasing therapeutic efficacy. The developed formulation overcome and alleviates the drawbacks and limitations of Abacavir sustained release formulations. The development of effective nano delivery systems capable of carrying a drug specifically and safely to a desired site of action is one of the most challenging tasks of pharmaceutical formulation investigators. On the basis of different parameters i.e. physicochemical and in-vitro release study, nanoparticles of batch NP4 are concluded as optimum formulations. Further, it can be concluded that the nanoparticulate formulation can be an innovative and promising approach for the delivery of Abacavir.

\section{AUTHOR'S CONTRIBUTION}

The manuscript was carried out, written, and approved in collaboration with all authors.

\section{ACKNOWLEDGEMENTS}

The authors extend their thanks and appreciation to the Ahmadu Bello University, P. M. B. 1045, Samaru, Zaria, Kaduna, Nigeria to provide necessary facilities for this work.

\section{CONFLICT OF INTEREST}

No conflict of interest was associated with this wor 


\section{REFERENCES}

1. Tamizhrasi S, Shukla A, Shivkumar T, Rathi V, Rath JC, Formulation and evaluation of lamivudine loaded polymethacrylic acid nanoparticles. Int J Pharm Tech Res 2009; 1(3): 411-415.

2. Yaowalak B, Ampol M, Bernd WM. Chitosan drug binding by ionic interaction. Eur J Pharm Sci 2006; 62, 267-74. https://doi.org/10.1016/j.ejpb.2012.04.007

3. Rauch A, Nolan D, Martin A. Prospective genetic screening decreases the incidence of abacavir hypersensitivity reactions in the Western Australian HIV cohort study. Clin Infect Dis 2006; 43(1): 99-102. https://doi.org/10.1086/504874

4. Heatherington. Genetic variations in HLA-B region and hypersensitivity reactions to abacavir. Lancet 2006; 359 (9312): 1121-1122. https://doi.org/10.1016/s0140-6736(02)08158-8

5. Mallal S, Phillips E, Carosi G. HLA-B5701 screening for hypersensitivity to abacavir. New England J Med 2008; 358 (6): 568-579.https://doi.org/10.1056/NEJMoa0706135

6. Kheradmandnia S, Vasheghani-Farahani E, Nosrati M, Atyabi F. Preparation and characterization of ketoprofenloaded solid lipid nanoparticles made from beeswax and carnauba wax. Nanomed Nanotechnol Biol Med 2010; 6:753-9. https://doi.org/10.1016/j.nano.2010.06.003

7. Min-Soo K, Shun-Ji J, Jeong-Soo K, Hee Jun P, Ha-Seung S, Reinhard HH. Neubert Sung-Joo Hwang. Preparation, characterization and in vivo evaluation of amorphous atorvastatin calcium nanoparticles using supercritical antisolvent (SAS) process. Eur J Pharm Biopharm 2008; 69, 454-465. https://doi.org/10.1016/j.ejpb.2008.01.007

8. Corsini A, Bellosta S, Baetta R, Fumagalli R, Paoletti R, Bernini F. New insights into the pharmacodynamic and pharmacokinetic properties of statins. Pharmcol Ther 1994; 84: 413-428. https://doi.org/10.1016/s0163-7258(99)00045-5

9. Schwarz C, Mehnert W. Freeze-drying of drug-free and drug-loaded solid lipid nanoparticles (SLN). Int J Pharmaceutics 1997; 157(2): 171-179. https://doi.org/10.1016/S0378-5173(97)00222-6

10. Shegokar R, Singh KK, Müller RH. Production and stability of stavudine solid lipid nanoparticles from lab to industrial scale. Int J Pharm 2011; 416: 461-470 https://doi.org/10.1016/j.ijpharm.2010.08.014

11. Mohanty C, Sahoo SK. The in vitro stability and in vivo pharmacokinetics of curcumin prepared as an aqueous nanoparticulate formulation. Biomaterials 2010; 31: 65976611. https://doi.org/10.1016/j.biomaterials.2010.04.062

12. Gourish C, Seth N, Sharma V. Nanoparticles and nanotechnology: clinical, toxicological, social, regulatory and other aspects of nanotechnology. J Drug Deliv Therap 2013; 3(4): 138-141.

https://doi.org/10.22270/jddt.v3i4.541 